\title{
Perceiving Academia's Decline Already in 1971
}

\section{Daniel Pipes}

I nominate Nathan Marsh Pusey, president of Harvard 1953-71, as the person who first foresaw and explained the modern American university's disastrous decline.

He did so elegantly and publicly in the course of reflecting on his tenure in his final commencement speech a half-century ago, on June 17, 1971. The talk received considerable attention, being published in full by the Boston Globe, ${ }^{1}$ covered by the New York Times, ${ }^{2}$ and discussed in a major history of Harvard. ${ }^{3}$

Pusey began by recalling the great hope for universities at the end of World War II and noted their considerable accomplishments in the sciences and in other fields. But then he added a somber consideration that jumps out a half-century later:

So we dreamed and so we worked. The effort has not come out exactly as we had hoped. At least not yet. But now a change has occurred, and as so frequently happens with the weather, the change was accompanied by storms. Universities are no longer universally admired. Indeed some people have even come to look upon them less as saviors than as the source of evils from which society must be saved. The general public evidences less esteem for university faculties.

It startles to realize that the academy's low reputation is not something recent but began so long ago. What had gone wrong? Pusey focused on "sharply critical students," his euphemism for extreme leftists:

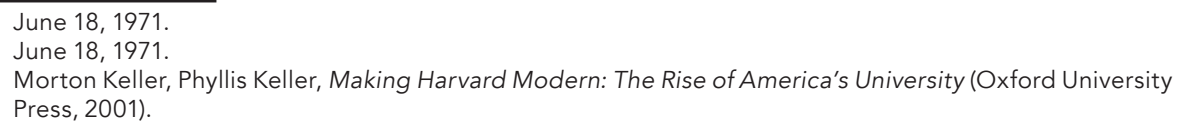

Daniel Pipes is president of the Middle East Forum and founder of Campus Watch: DanielPipes.org, @DanielPipes, daniel.pipes@gmail.com. His last article for Academic Questions, "Getting Bashar alAssad Very Wrong," appeared in the Spring 2021 issue. 
A growing number of students are less readily impressed by what professors have to offer and less ready to devote sustained attention to their teaching. These sharply critical students are also less convinced of the integrity and validity of society's institutions, including its colleges and universities; and they are less ready to work in and for them, on established terms, than were the young who for the most part were happy to be attending and serving these same institutions just a few years ago.

Pusey noted the profundity of the challenge: "The aims and methods of universities have come into question-fundamentally." He anticipated how, over time, those radicals would transform the American university for the worse: "There can be no doubt that we are entering a new, very different, and, it appears, a very troubled period in higher education." That "very troubled period in higher education” remains very much with us a half-century later, indeed more troubled than ever and with no sign of letting up.

Pusey correctly predicted "an era of radically altered conditions, sharp change, and formidable obstacles" and twin crises of scholarship and personnel:

There is also less confidence that universities can or will want to produce the requisite knowledge. And there is even less confidence that, if they knew how and wanted to produce the knowledge, they could also produce the people with the stamina and character to put it to work to accomplish the constructive ends.

The lack of people with "stamina and character" drove Pusey to a "gloomy" conclusion about the future of the American university:

Because so many currently question the value of universities and their ability, in the face of challenge, criticism and increased financial stringency, to continue to serve in their ancient and honorable tradition, it would be easy to feel gloomy about their prospects. 
In other words, his bitter experience with the play-revolutionaries of 196971 gave Pusey the special insight to predict that this cohort would fundamentally change the nature of higher education for the worse. ${ }^{4}$

Judging by the New York Times's account of this speech, Pusey's audience missed its point. Bill Kovach reported that Pusey had "reviewed his 18-year tenure as one covering a time in which universities were transformed, in the eyes of the public, from the source of hope for a better world to fumbling institutions that could not meet the challenge." Fumbling hardly does justice to this scathing indictment.

To the extent he is now remembered, Nathan Pusey (1907-2001) is recalled for successfully standing up to Joseph McCarthy in the early 1950s, then failing to handle student rioters in the late 1960s, leading to his exhaustion and "premature retirement." ${ }^{5}$ Instead, he should be remembered for a deep analysis of the university's predicament; before anyone else, he prophetically inferred on the record from the radical leftism of his final years at Harvard that there was to be a "very troubled period" ahead.

Now, if he were only around to tell us when it will end. 